\title{
Monseñor Romero y la escatología de Gaudium et Spes
}

\author{
Ramón Sala \\ ESCUELA DE TEOLOGÍA \\ UNIVERSIDAD TEOLÓGICA DE AMÉRICA CENTRAL \\ "MONSEÑOR OSCAR A. ROMERO" (SAN JOSÉ, COSTA RICA) \\ rssala@gmail.com
}

\begin{abstract}
Resumen: El Arzobispo de San Salvador, Beato Mons Oscar A. Romero (1917-1980), además de pastor y mártir de los pobres, fue un profeta y un maestro, que "sentía con la Iglesia" del Concilio Vaticano II. Muchas de las enseñanzas contenidas en sus homilías están inspiradas directamente en la visión escatológica de la Constitución pastoral Gaudium et Spes. La suya es una contribución a la recepción de un documento que nació con la vocación de ser continuamente actualizado e inculturado (cf. GS 91b).
\end{abstract}

Palabras clave: Mons. Romero, Escatología, Vaticano II, Gaudium et Spes.

Abstract: The Archibishop of San Salvador, Blessed Mons. Oscar A. Romero (1917-1980) was not only the Pastor and Martir of the Poor, but also a Prophet and a Master, who "felt with the Church" of the Second Vatican Council. A lot of his teachings, taken from his Homilies, are straight inspired on the eschatological approach of the Pastoral Constitution Gaudium et Spes. He offers a contribution for the reception of a document that was born to be continously updated and inculturated (cf. GS 91b).

Keywords: Mons. Romero, Eschatology, Vatican II, Gaudium et Spes.

\section{INTRODUCCIÓN}

Haciendo un balance de la situación de la escatología católica en vísperas del Vaticano II, H. Urs von Balthasar constataba en 1957 que se estaban registrando ya una serie de cambios que perfilaban una renovación. Lo escatológico estaba pasando de ser una disciplina regional a convertirse en una categoría transversal de toda la teología; de una perspectiva puramente futurista, a una de presente; de un planteamiento esencialista, a adoptar un carácter existencial; de estar centrado en las postrimerías 
(cosas o lugares últimos), a la clave personalista; de un interés individualista, a uno universalista; en fin, de un discurso afirmativo y apodíctico, a otro más cuestionante y modesto ${ }^{1}$.

Aunque entre los esquemas preparatorios del Vaticano II había uno con un capítulo dedicado a "De Novissimis", ninguno de los documentos conciliares trata específicamente de esta materia. Ahora bien, el Concilio ha producido dos importantes grupos de textos escatológicos: el cap. VII de la Constitución Lumen Gentium ("Índole escatológica de la Iglesia”) y varios números de la primera parte de la Constitución pastoral Gaudium et Spes (GS). Son esos últimos textos (GS 4, 10, 18, 21, $22,32,38,39,43,45)$ los que recogen más claramente aquellos nuevos planteamientos, gracias a su estrecha conexión con la cristología y la antropología teológica.

Fruto de la doctrina conciliar, las llamadas "teologías de la praxis" se concentraron después inequívocamente en el componente escatológico del presente. Ya sea para salvaguardar la fe frente al mundo de la increencia postilustrada, como en la teología política (J. B. Metz); para profundizar en el carácter pascual de la esperanza cristiana, como el tema propio de la escatología (J. Moltmann); o bien, para hacerla activa en el compromiso por los pobres y excluidos, como en la teología de la liberación (G. Gutiérrez). Como no podía ser de otro modo, dado el contexto sociocultural de su ministerio, en esta última línea hay que situar el pensamiento escatológico del beato Romero ${ }^{3}$. El presente estudio, de carácter sincrónico, se circunscribe solamente a sus homilías como arzobispo (1977-1980) .

Es sabido que Monseñor Romero no estuvo presente en las sesiones conciliares, pero no hace falta insistir en que fue un obispo del Vaticano

1 Cf. H. Urs von Balthasar, "Escatología" en J. Feiner y otros, dir., Panorama de la teología actual (Guadarrama, Madrid 1961) 499-518.

2 Era el cap. IX del esquema De deposito fidei pure custodiendo (cf. Acta et Documenta IIIII, I, 54-89).

3 "Mons. Romero se mantuvo más bien al nivel de la teología del Vaticano II, aunque sus contenidos teológicos reales eran también bíblicos e históricos, y respondían a la mejor intención de la teología de la liberación” (J. Sobrino, Monseñor Romero [UCA, San Salvador $\left.{ }^{2} 1994\right]$ 39).

4 Cf. O. A. Romero, Su pensamiento. Colección de homilias y diario, vols. I-VIII (UCA, San Salvador 2000). En las citas, el volumen se indica en números romanos y las páginas en cifras árabes. 
II. Vivió el ambiente conciliar en Roma en su etapa de estudiante en la Pontificia Universidad Gregoriana. Conoció personalmente a muchos de los protagonistas más directos del Concilio. Estudió y asimiló sus documentos como exigencia del lema que había escogido para su episcopado ("sentire cum Ecclesid") y como guía de su ministerio pastoral. Por eso se comprende que entre los documentos conciliares, sea precisamente la Constitución pastoral uno de los más citados en sus homilías ${ }^{5}$. Y sobre todo, Monseñor Romero supo vislumbrar proféticamente durante el postconcilio los signos de los tiempos (cf. GS 4; 11), a pesar de acusaciones, calumnias y amenazas que le llevaron hasta el martirio ${ }^{6}$. Es decir, reconoció, a la luz del evangelio, las consecuencias que se derivan de la misión de una Iglesia que, por fidelidad a Cristo, hace propia la causa y el destino de los pobres en el mundo de hoy.

\section{LA PERSPECTIVA ESCATOLÓGICA}

\subsection{Lo escatológico en Gaudium et spes}

El tema de GS no es "el mundo actual", tampoco "la Iglesia y el mundo". Su objeto es el que da título al cap. IV de la primera parte: la misión de la Iglesia en el mundo de hoy. Muy bien lo explicaba Mons. Romero, comentando GS 1, estrenando su ministerio pastoral como Arzobispo de San Salvador. A propósito de "la Iglesia, Cuerpo de Cristo en la historia”, decía así:

La Iglesia ha comprendido que vivía un poco de espaldas al mundo y se convierte para dialogar con el mundo. Y en el Concilio Vaticano II escribe toda una hermosa Constitución que se llama así: la Iglesia en el mundo actual. La Iglesia no es una extraña del mundo. Todo lo humano toca su corazón y ella siente que ha de convertirse a un diálogo más evidente con este mundo que le debe de interesar. Son ustedes, sobre todo los pobres, los que sufren, los que son atropellados, los marginados, los sin voz. Y la Iglesia se identifica con este

5 Hemos contabilizado hasta una treintena de referencias textuales explícitas de GS. Los textos de la Constitución pastoral se citan según la versión española de la web oficial de la Santa Sede (www.vatican.va). Las letras indican el párrafo del número correspondiente del documento.

6 Cf. T. Greenan, El pensamiento teológico-pastoral en las homilias de Monseñor Romero (UCA, San Salvador 1998) 179-180. 
mundo que sufre, pero no exclusivamente. Con todos los hombres que construyen el mundo ${ }^{7}$.

Para Mons. Romero, el "mundo" al que se dirige la Iglesia en GS es una realidad antropológica y social, el mundo de los hombres, "la familia humana” (GS 2b), en particular el mundo de los pobres y los que sufren, con quienes ella se identifica de un modo especial ${ }^{8}$. Con motivo de la fiesta del Divino Salvador del Mundo, patrono de su país, Mons. Romero proclamaba que "para la Iglesia no existe en esta tierra, en esta historia, ese mundo definitivo, pero sí se pide que se refleje, en esta historia, ese mundo definitivo que estamos esperando" 9 .

Entre los interrogantes que la humanidad se ha planteado siempre, la Constitución pastoral destaca la cuestión del destino último de la vida humana (cf. GS 3a; 10a). La respuesta del ateísmo, considerando irreconciliable la libertad con el reconocimiento de Dios como "fin de todas las cosas", consiste en proclamar al ser humano "el fin de sí mismo, el único artífice y creador de su propia historia” (GS 20a). En cambio, la misma experiencia humana, en sintonía con la Revelación cristiana, descubre que precisamente el origen del mal en el mundo se debe a la pretensión humana de lograr su propio fin último al margen de Dios (cf. GS 13a).

Ya las palabras iniciales que dan nombre a la Constitución pastoral indican que la perspectiva dominante de toda su exposición es la que apunta al futuro con esperanza. La esperanza de la humanidad penetra todo el documento, de principio a fin (cf. GS 93a), según la intención manifestada expresamente por los redactores de la Subcomisión central del Concilio que en Ariccia, antes del último período de sesiones del Concilio (1965), decidieron modificar significativamente el orden de la formulación inicial del llamado "Texto de Zurich". En lugar de la expresión neutra "Gaudium et luctus, spes et angor" de la redacción previa,

Homilía del 6 de agosto de 1977 (I-II, 153).

8 En la que sería su última carta, escrita a máquina pocas horas antes de su muerte, agradeciendo a Mons. Casaldáliga su fraternal cercanía con motivo de la destrucción de la emisora de la Arquidiócesis, alude a GS 1 con estas palabras: "Su calurosa adhesión alienta considerablemente la fidelidad a nuestra misión de continuar siendo expresión de las esperanzas y angustias de los pobres, alegres de correr como Jesús los mismos riesgos, por identificarnos con las causas de los desposeídos" (citado por J. Sobrino, Monseñor Romero, 46-47).

$9 \quad$ Homilia del 7 de agosto de 1977 (I-II, 167). 
la nueva y definitiva dice ahora: "Gaudium et spes, luctus et angor"10. Una esperanza sustentada en Dios mismo como destino último del hombre (cf. GS 24a; 29a; 41a). Y el reconocimiento de esa realidad, lejos de menoscabar la dignidad humana, al contrario, la perfecciona (cf. GS 21c).

Es decir, frente a la visión reductiva de las esperanzas meramente intrahistóricas, comunes a los humanismos ateos (existencialistas o marxistas), la Constitución pastoral, en diálogo con esas mismas corrientes del pensamiento contemporáneo, enseña que la esperanza cristiana no se opone a las esperanzas terrenas, sino que las completa, acogiéndolas y superándolas, desde una visión escatológica centrada en el futuro absoluto que es Dios. La originalidad de la fe cristiana reside concretamente en su inamovible "spes contra spem" (Rm 4,18; cf. Hb 11,1). Como la meta de la fe es la esperanza y, a su vez, la esperanza permanece siempre enraizada en la fe, para el cristianismo la esperanza del ser humano tiene como fin último la comunión con Dios en la vida eterna ${ }^{11}$. Solamente Dios puede responder "a las aspiraciones más profundas del corazón humano" que ninguna meta terrestre puede colmar plenamente (GS 41a). El párrafo final de GS 21 insiste en esa convicción, apoyándose en la célebre plegaria agustiniana: "Nos hiciste, Señor, para ti y nuestro corazón está inquieto hasta que descanse en ti” (Confesiones I,1,1) 12 .

\subsection{La noción "escatología”}

El mundo contemporáneo es un mundo abierto al porvenir. La historia ha dejado de ser recuerdo; hoy es más bien proyección hacia el futuro ${ }^{13}$. Y esa apertura al porvenir, para la escatología cristiana, es metahistórica aunque inseparablemente unida a su actualidad y urgencia histórica. Para Mons. Romero, la escatología "es el último acto de Dios para darle a la historia su sentido final"14. En muchas de sus homilías él explica a

10 Cf. Acta Synodalia III, V, 116; Acta Synodalia IV, I, 435.

11 Cf. F. Dingjan, "Christliche Hoffnung in einen weltlichen Welt nach Gaudium et Spes": Studia Moralia 7 (1969) 258-262.

12 Cf. nota 19. Cf. Homilía del 27 de mayo de 1979, VI, 381; Homilía del 24 de agosto de 1979, VII, 201.

13 " $[. .$.$] la historia es una continua madre dando a luz, algo viejo muere y algo nue-$ vo hace [sic] siempre en la historia" (Homilia del 18 de noviembre de 1979, VII, 455). Cf. G. Gutiérrez, Teología de la liberación. Perspectivas (Sígueme, Salamanca ${ }^{13} 1987$ ) 275-279.

14 Homilía del 6 de noviembre de 1977 (I-II, 313). 
los fieles el significado del término "escatología": "es lo último, lo definitivo, el final de la historia, el reino definitivo de Cristo"; "lo último, lo que está más allá de la historia, lo definitivo, la meta hacia la que camina toda vida de hombre y toda historia y todo pueblo". "Significa lo último, la finalidad de la historia y del hombre, hacia donde marcha esta sociedad, esta Iglesia".

Siempre que les he predicado de "escatología" les he dicho, queridos hermanos, que es lo último, como la última perspectiva de la historia. Pero que no hay que esperar a que termine la historia para tener esa perspectiva escatológica. Es como el que mira, desde la mitad del camino, la meta hacia dónde se dirige; ya la tiene en su mente y, gracias a esa meta escatológica, lo último, va caminando con esperanza $\mathrm{y}$ con confianza que sabe a dónde lleva ese camino ${ }^{15}$.

Mons. Romero no presenta lo escatológico solamente "como una esperanza más allá de la muerte, como una eternidad que estamos esperando" ${ }^{16}$. Para él, la perspectiva escatológica no es futurología. Siempre mira al presente de la historia. Apunta al futuro sí, pero para iluminar el presente desde su meta y destino último.

Por otra parte, la predicación del Arzobispo de San Salvador destaca también la dimensión comunitaria de la escatología. Caracterizando a la Iglesia en el mundo actual como "una comunidad en espera activa del retorno de Cristo”, decía Monseñor:

Uno de los mensajes más apremiantes de la Iglesia de hoy es que los cristianos salgan de una mentalidad individualista. Que ya no hablemos de mi salvación, mi religión, sino que la vivamos como Dios quiere, que la vivamos en pueblo. Nuestra salvación, [en] nuestro peregrinar por la historia vamos como pueblo, como el pueblo israelita por el desierto iba junto, comunitariamente, así vamos [...] una comunidad en espera. ¿Qué quiere decir? Es la característica del cristiano. Por eso se llama comunidad escatológica, ciencia de lo último, comunidad que vive pendiente del desarrollo hasta la última consecuencia. ¿¿Hacia dónde va la historia? ¿Hacia dónde va mi vida? ¿Hacia dónde va esta Iglesia? Lo escatológico ${ }^{17}$.

15 Homilia del 14 de abril de 1979 (VI, 306-307). Cf. Homilia del 13 de noviembre de 1977 (I-II, 319); Homilía del 17 de junio de 1979 (VI, 432); Homilía del 29 de julio de 1979 (VII, 112).

16 Homilia del 29 de julio de 1979 (VII, 112).

17 Homilía del 19 de noviembre de 1978 (V, 308-309). 
La Iglesia, encarnada en la historia, "tiene una finalidad escatológica y de salvación que sólo en el mundo futuro podrá alcanzar plenamente" (GS 40b). Una de las primeras homilías de Mons. Romero lleva por título: "La Iglesia escatológica"18. Con ese calificativo se expresa bien la condición peregrinante del tiempo de la Iglesia. Pero, para ilustrar de un modo más elocuente esa enseñanza, recurrirá después a dos bellas imágenes. La primera, inspirada en el Cántico Espiritual de san Juan de la Cruz, presenta a la Iglesia como la esposa que suspira por el Esposo ausente $^{19}$. En la otra, se refiere a la aurora que anuncia la llegada del nuevo día ${ }^{20}$.

En síntesis, en la línea marcada por la doctrina conciliar, para Mons. Romero lo escatológico lee la historia desde la perspectiva del destino último y definitivo del hombre y del mundo. Un destino metahistórico hacia el que se dirige la Iglesia -guiada por el Espíritu Santo y en solidaridad con el género humano-, como comunidad escatológica, peregrina en el mundo "hacia el reino del Padre" (GS 1; cf. 3b; 11a; 21e; 26d; 40b; $41 \mathrm{a} ; 43 \mathrm{f})$. Por tanto, hay una coincidencia fundamental entre la enseñanza del Arzobispo mártir y la concepción predominantemente escatológica de la historia que caracteriza a la Constitución pastoral, según sus comentaristas $^{21}$.

\section{El FUNDAMENTO CRISTOLÓGICO DE LA ESCATOLOGÍA}

\subsection{La plenitud de la humanidad en Cristo}

El cristianismo no es un conjunto de verdades que hay que creer, de leyes que hay que cumplir, de prohibiciones [...] El cristianismo es una persona [...] El cristianismo es Cristo [...] A la luz de Cristo, se comprende lo escatológico, un hermano mayor que me está esperando, más aun, que ya va conmigo. Porque cuando hablamos de escatología quisiera grabar esta otra idea: lo escatológico no es sólo lo que se espera; lo escatológico es lo que ya se tiene, cuando se tiene fe,

18 Cf. Homilía del 6 de noviembre de 1977 (I-II, 312-313).

19 Homilía del 13 de noviembre de 1977 (I-II, 321).

20 Homilia del 19 de noviembre de 1978 (V, 313).

21 Cf. V. Alesiani, Vocazione storica ed escatologica dell'uomo nella "Gaudium et Spes", Ex. Diss. PUL (Roma 1975); F. DingJan, "Christliche Hoffnung in einen weltlichen Welt nach Gaudium et Spes”, 237-263; A. A. Dos Santos Marto, Esperança cristã e futuro do homem. Doutrina escatológica do Concilio Vaticano II, Diss. PUG (Porto 1987). 
a Cristo en el corazón. No esperamos morir para ser felices, ya somos felices cuando tenemos el Reino de Dios, como decía Cristo, "en nuestros corazones". Cuando Cristo vino, hace veinte siglos, comenzó la escatología. Es el último acto de Dios para darle a la historia su sentido final. El sentido final de la historia, el sentido relativo de todas las cosas [penúltimas] lo da Cristo: instaurar todas las cosas en Cristo. Sólo aquello que se va apegando a Cristo ya está siendo escatológico $[\ldots]^{22}$.

Tanto la antropología como la escatología de GS son abiertamente cristocéntricas. Cristo es el fundamento de nuestra esperanza porque solamente Él descubre al hombre la grandeza de su vocación última, que es una vocación divina (cf. GS 22a; 22f). Asumiendo plenamente la condición humana, hasta el abismo supremo de la muerte, y resucitando a la vida de Dios, Cristo ha trazado el camino que da un significado nuevo tanto a la vida como a la muerte (cf. GS 22d). Él asegura que la comunión vital con Dios es el cumplimiento de la vocación escatológica del hombre: al empeño histórico y a la vida eterna, a la gracia y a la gloria.

Comentando GS 22, para muchos autores el texto cristológico más importante del Vaticano II, Mons. Romero decía que, sin Cristo, el hombre es "un absurdo":

El misterio del hombre, dice el Concilio Vaticano II en una frase genial: "el misterio del hombre solamente puede esclarecerse por el misterio del Dios que se hizo hombre"; si no fuera por Cristo, el Hijo del hombre, todos los hombres no seríamos más que un absurdo. Si tienen sentido las luchas reivindicativas de la dignidad, de la libertad, de la igualdad de los hombres, solamente será a la luz de Cristo"23.

Siguiendo el "genial" texto de la Constitución Pastoral, Monseñor proclama que solo en Cristo descubrimos quién es el hombre. Según la antropología cristiana, no hay antropología sin cristología. Cristo entra en la definición del hombre. Y como Él es imagen de Dios (Col 1,15), para Mons. Romero, el hombre es un "retrato de Dios". Por eso, cuando el ser humano, a causa del pecado, se olvida de Cristo, convierte todas

\footnotetext{
Homilía del 6 de noviembre de 1977 (I/II, 312-313).

23 Homilía del 27 de mayo de 1979 (VI, 381).
} 
sus capacidades "en un sistema de opresión, de esclavitud, de odio, de venganzas" 24 .

Cristo es nuestro Eschaton personal. "Solo aquellos que vivan conforme a Cristo, ya en esta vida, serán arrancados para la vida eterna"25. En su última Vigilia Pascual, Mons. Romero insistía en el fundamento cristológico de la esperanza cristiana, invitando a fijar la mirada en el Resucitado:

Eso ha hecho Cristo resucitado. Poner en el vaivén de la historia, entre las cosas transitorias que van y vienen, lo eterno de su vida. Su vida de resucitado, que no morirá más, pertenece a este mundo y dichosos los hombres que saben dar a su vida un sentido escatológico. Es decir, mirar en Cristo resucitado la meta hacia donde camino; con mis pobrezas, con mis tribulaciones, con mis ansias de liberación. Aferrado a ese Cristo no puedo fallar. Cristo le da fuerza, le da espíritu a esa lucha por un mundo mejor ${ }^{26}$.

\subsection{Cristo, centro y fin de toda la historia humana}

Este fue el tema de la homilía que pronunció Monseñor el segundo domingo de Adviento de 1977. En ella comentaba el texto conclusivo de la "Exposición preliminar" de la Constitución pastoral. A propósito de los múltiples "desequilibrios que fatigan al mundo moderno", Mons. Romero comenzaba recordando cómo GS 10a -el párrafo más extenso de todos los números de la Constitución pastoral- señala que son causados por un "desequilibrio fundamental que hunde sus raíces en el corazón humano". En efecto, el ser humano, "llamado a una vida superior", se experimenta dividido interiormente, víctima del poder destructivo de los materialismos prácticos (cf. GS 19-21) y, también, en otros muchos casos, de la miseria:

Ven los dos grandes males de hoy: el vivir tan cómodos, tan instalados, tan ricos que prácticamente son materialistas [...] están muy a gusto en sus jaulas de oro. Y por otra parte, la demasiada miseria no deja tiempo para ponerse a considerar ¿Qué tiempo va a tener el pobrecito que está pensando hoy a ver si mañana encuentra trabajo [...] $y$, en vez de trabajo, tal vez encuentra la prisión, el desaparecimiento.

\footnotetext{
24 Homilia del 25 de diciembre de 1977 (III, 98).

25 Homilia del 27 de noviembre de 1977 (III, 11).

26 Homilía del 14 de abril de 1979 (VI, 307).
} 
"Otros esperan del solo esfuerzo humano la verdadera y plena liberación de la humanidad y abrigan el convencimiento de que el futuro reino del hombre sobre la tierra saciará plenamente todos sus deseos". Esta es la ilusión de unas liberaciones que no piensan en Dios, sino que todo lo hacen consistir en la revolución, en las fuerzas de la tierra, y es también el error de otro ateísmo práctico, porque el materialismo [...] tampoco tiene tiempo de ver a Dios y cree que aquí se puede encontrar el paraíso en la tierra $[\ldots]^{27}$.

Frente a estas esperanzas solamente intrahistóricas, GS proclama un destino trascendente del ser humano y del mundo más allá de la historia. En el plan salvífico de Dios, Cristo es "Alfa y Omega". No solo el principio, sino también el fin de todo (cf. Ap 1,8; 21,6; 22,13). Todo fue hecho mediante Él y todo camina hacia Él (cf. 1Cor 8,6; Col 1,15-20; Ef 1,3-10; Jn 1,3.10; Hb 1,3). En GS 45bc aparece expresada claramente esta orientación cristológica de la escatología cristiana. La cristología de GS es una "cristología de la recapitulación" 28 . Cristo es el origen de la Creación y con su encarnación redentora ha realizado ya su sentido último. Por eso, es también el evento final (Eschatos) en el que todo será consumado. Con la Resurrección de Cristo ha aparecido ya la realidad última (Eschaton) y han llegado ya los últimos tiempos (Eschata). En Cristo, la historia tiene un fin personal y no solo un final cronológico. En virtud del misterio pascual, el mundo y la historia humana están destinados a ser transformados, según el plan divino, para alcanzar su consumación (cf. GS 2b).

Mons. Romero presentaba a Cristo como clave del destino último del mundo, repasando la pedagogía divina de la salvación a propósito de la esperanza de la Iglesia en "el día del Señor":

Ya se anunció en el Antiguo Testamento muchas veces, y lo hemos comentado aquí. El día del Señor. Los profetas hablaban [del] día del Señor como un día en que Dios nos espera con los brazos abiertos para premiar nuestros méritos buenos o nos espera con su ira para castigar nuestras almas $[s i c]$ acciones. El día del Señor en el pasado, como todavía no había venido Cristo, era muy nebuloso. Los profetas no tuvieron la dicha que nosotros, cristianos, tenemos de conocer

27 Homilía del 4 de diciembre de 1977 (III, 23-24).

28 Cf. T. GertLer, Jesus Christus. Die Antwort der Kirche auf die Frage nach dem Menschsein. Eine Untersuchung zu Funktion und Inhalt der Christologie in ersten Teil der Pastoralkonstitution "Gaudium et Spes” des zweiten vaticanischen Konzils (St. Benno, Leipzig 1986). Significativamente Ef 1,10 es el versículo de la Biblia citado más veces por GS. 
que Cristo, que ya vino hace veinte siglos, es el que vino a iniciar el día del Señor. Vivimos ya la última fase de la historia. Cristo es [...] la clave, el desenlace, la meta, el día del Señor ${ }^{29}$.

Resumiendo su predicación del segundo domingo de Adviento de 1977, antes mencionada, Monseñor retomaba textualmente las palabras de GS $10 b^{30}$. Y repetía la cita de ese mismo texto de la Constitución pastoral el domingo siguiente para insistir en el fundamento cristológico de toda liberación humana ${ }^{31}$. Sin Cristo no hay verdadera liberación.

\section{UnA escatología (Del) PRESEnTE}

\subsection{La "hora escatológica"}

Para Mons. Romero, a partir de la Resurrección de Cristo, en el presente de la historia estamos viviendo ya el tiempo escatológico, que tendrá su consumación con la parusía del Señor. Él lo llama la "hora escatológica":

Seamos cristianos de verdad, dignos de esta hora escatológica que va desde la venida primera de Cristo hasta la segunda, pedido último de la historia, sepamos vivirlo como quien vive algo que no es permanente, sino que va de paso. No instalarse, no apegarse, no perder por los bienes del poder de la tierra, los encantos del reino de Dios que ya viene a asumirnos $[\ldots]^{32}$.

Esta es la hora que hay que vivir, queridos hermanos, no estamos todavía en el cielo. Cierto que tenemos, como Iglesia, la garantía de que Cristo vive en nosotros, pero es un Cristo oculto [...] Es la esposa enamorada que desde el destierro clama para darle un beso, darle un abrazo, vivir para siempre unida con Él ${ }^{33}$.

Monseñor explicaba a los fieles el significado de la parusía, comentando dos parábolas de Mt 25: la de las diez vírgenes y la del juicio final (cf. LG 48d). Con la primera (Mt 25,1-13) ponía de relieve la conveniente disposición personal para el encuentro final con el Señor que viene, simbolizado en las lámparas encendidas:

29 Homilía del 19 de noviembre de $1978(\mathrm{~V}, 310)$.

30 Homilía del 4 de diciembre de 1977 (III, 24).

31 Homilía del 11 de diciembre de 1977 (III, 55). Cf. Homilía del 18 de noviembre de 1979 (VII, 451); Homilia del 17 de febrero de 1980 (VIII, 237-238).

32 Homilía del 27 de noviembre de 1977 (III, 12).

33 Homilía del 12 de noviembre de 1978 (V, 298). 
La hora que la antigua teología llamó con una palabra griega muy simbólica, la "parusía". Era la palabra griega con que se designaba el aparecimiento de un Dios oculto o la llegada de un emperador, de un gobernante a una ciudad y se le preparaba un gran recibimiento [...] La venida de Cristo cuando viene a recoger nuestra vida en la hora de nuestra muerte es la parusía, es el encuentro, es la espera de la vida que va a culminar en un encuentro [...] ¡Hay de nosotros si, a la hora de la parusía, Cristo nos encuentra con la lámpara apagada y sin aceite, con el alma en pecado, con la vida desprevenida! ${ }^{4}$.

En la parábola del juicio final (Mt 25,31-46), invocada en varias ocasiones por Mons. Romero, subrayaba, sobre todo, el reconocimiento ya actual de Cristo mismo, encarnado en aquellos con quienes Él se identifica (cf. LG 8c; GS 27b; 88a) ${ }^{35}$. Interpreta así sus duras palabras de la segunda parte del pasaje mateano: "Apartáos malditos, al fuego eterno, porque tuve hambre y no me distéis de comer, es decir, no vivísteis la escatología con el sentido cristiano que yo quise al venir a la tierra a encarnarme, a hacerme hombre, morir por los hombres, resucitar para darles nueva vida y darles un mensaje de liberación" 36 .

Según Monseñor, lo interesante es que ambas parábolas destacan el valor de las tareas temporales desde una perspectiva escatológica. Es lo que él denomina "escatología presente" o "escatología del presente":

Por eso en la Iglesia es clásico ese movimiento que se expresa con estas palabras: "Ya, todavía no" ${ }^{37}$, como el péndulo de un reloj: "Ya, todavía no", "ya, todavía no". Ese es el cristianismo: "Ya”, ya debo vivir como si viviera en el cielo; "todavía no", porque no se ha manifestado lo que soy; ya, siento mi compromiso con este Cristo encarnándose en este pueblo al que debo servir y dar mi vida, aunque no veo el esplendor de la gloria que llevo encendida en mí mismo. Todo aquel que ahora está en gracia de Dios y que se va a acercar a la comunión,

\footnotetext{
34 Homilía del 12 de noviembre de 1978 (V, 298).

35 "Nada hay tan importante para la Iglesia como la vida humana, como la persona humana. Sobre todo, la persona de los pobres y oprimidos que, además de ser seres humanos, son también seres divinos, por cuanto en ellos dijo Jesús que todo lo que con ellos se hace, Él lo recibe como hecho a Él" (Homilía del 16 de marzo de 1980, VIII, 349).

36 Homilía del 27 de noviembre de 1977 (III, 12).

37 Como es sabido, esta afortunada expresión ("Schön, aber noch nicht”) fue introducida por el teólogo protestante O. Cullmann para ilustrar la llamada "tensión escatológica".
} 
ya vive el Reino de Dios, pero todavía no se le ve lo que es, pero ya lo lleva escondido en su corazón. Esto se llama escatología presente, o sea, que la escatología tiene dos momentos: un presente y un futuro; el presente lo vive la gente de fe, de esperanza. En la marginación, en la pobreza y en la humillación, en la tortura, el hambre ya está viviendo ese cielo, esa esperanza ${ }^{38}$.

La presencia del Reino de Dios en la historia, según Mons. Romero, es el signo de que "se está elaborando ya la suerte definitiva de los hombres"39. La escatología final ("de la epifanía”, "de la parusía”, "del apocalipsis") hay que vivirla ya, porque "la escatología no es solo esperar un futuro; hay una escatología del presente" ${ }^{\text {. }}$.

En una de sus homilías sobre la esperanza cristiana, el beato Monseñor utiliza el relato de un viaje de un papá con su hijo para facilitar a los fieles la comprensión de esta enseñanza. Dios es como un padre que señala metas inmediatas para animar al ser humano (hijo) durante el largo trayecto hacia su destino final.

[...] es la pedagogía del papá con el hijo que tiene que hacer un viaje muy largo y para que no se desanime le cuenta las bellezas de aquella ciudad a donde van [...] pero el niño se cansa. Entonces el papá comienza a decirle: "Mira, sólo vamos a llegar hasta aquella cumbre, después de esa cumbre está el reino tan bonito que te he descrito". Y cuando, con el niño, llega a la cumbre, todavía le dice: "Es más allá, un poquito" $" 11$.

Sin embargo, el empeño de Mons. Romero durante su ministerio episcopal por las conquistas temporales para su pueblo, como etapas en el camino del Reino, no solo fue incomprendido, sino que acarreó dos graves acusaciones contra su persona y contra la Iglesia salvadoreña: la de meterse en política y la de propugnar la ideología comunista. En varias de sus homilías, el pastor se vio obligado a defenderse de ambas.

Respecto a la segunda acusación, desde la visión escatológica de una Iglesia que "conserva su mirada siempre en alto", Mons. Romero

\footnotetext{
38 Homilía del 6 de noviembre de 1977 (I-II, 313).

39 Homilía del 29 de julio de 1979 (VII, 112).

40 Homilía del 19 de noviembre de 1978 (V, 322).

41 Homilía del 18 de noviembre de 1979 (VII, 449-450).
} 
la considera "ridícula" espiritualidad que solamente piensa en el cielo" y descalifican con ese apelativo "todo esfuerzo de la Iglesia en la tierra"

La Iglesia "no hace política. Ella se acerca a la política para defender al hombre en su trascendencia" ${ }^{44}$. Todavía la víspera de su muerte, en su célebre última homilía en la catedral el quinto domingo de Cuaresma de 1980, Monseñor rechazaba los ataques a la misión temporal de la Iglesia, predicando sobre su "servicio de liberación personal, comunitaria y trascendente":

Nadie tome a mal que, a la luz de las palabras divinas que se leen en nuestra misa, iluminemos las realidades sociales, políticas y económicas, porque de no hacerlo así, no sería un cristianismo para nosotros. Y es así como Cristo ha querido encarnarse para que sea luz que Él trae del Padre, se haga vida de los hombres y de los pueblos. Ya se que hay muchos que se escandalizan de estas palabras y quieren acusarla [a la Iglesia] de que ha dejado la predicación del evangelio para meterse en política, pero no acepto yo esta acusación, sino que hago un esfuerzo para que todo lo que nos ha querido impulsar el Concilio Vaticano II, la reunión de Medellín y de Puebla, no sólo lo tengamos en las páginas y lo estudiemos teóricamente, sino que lo vivamos y lo traduzcamos en esta conflictiva realidad de predicar como se debe el evangelio $[. .$.$] para nuestro pueblo. Por eso, le pido al Señor durante$ toda la semana, mientras voy recogiendo el clamor del pueblo y el dolor de tanto crimen, la ignominia de tanta violencia, que me dé la palabra oportuna para consolar, para denunciar, para llamar al arrepentimiento y aunque siga siendo una voz que clama en el desierto, sé que la Iglesia está haciendo el esfuerzo por cumplir con su misión $[\ldots]^{45}$.

"La Iglesia esperando su cielo, no se olvida de la tierra" ${ }^{46}$. En defensa del compromiso temporal de la Iglesia, Mons. Romero invoca a menudo el texto de GS 43. En particular, cita repetidamente el pasaje de su

42 "Desde esta perspectiva [eterna] la Iglesia se define y no se confunde con los movimientos liberacionistas de la tierra. Por eso es ridículo decir que los sacerdotes son comunistas. Es ridículo decir que un catequista que predica la doctrina de la Iglesia se vuelve marxista" (Homilía del 13 de noviembre de 1977, I-II, 319).

43 Homilía del 24 de septiembre de 1978 (V, 208).

44 Homilía del 27 de mayo de 1979 (VI, 380).

45 Homilía del 23 de marzo de 1980 (VIII, 360-361).

46 Homilía del 13 de noviembre de 1977 (I-II, 321). 
primer párrafo que lanza la siguiente advertencia: "el cristiano que falta a sus obligaciones temporales, falta a sus deberes con el prójimo; falta, sobre todo, a sus obligaciones para con Dios y pone en peligro su eterna salvación" (GS 43a).

Tenemos una doble vocación: "para vivir con felicidad y dignidad en esta tierra y para un destino feliz más allá de la historia" ${ }^{47}$; somos ciudadanos de dos ciudades:

Aquí es, hermanos, donde yo quiero reivindicar para la Iglesia esa misión tan difícil, pero tan necesaria, de predicar al mundo presente sus deberes temporales. Cuando el Concilio habla de que la Iglesia está en el mundo para servirle al mundo, el mayor servicio es precisamente éste: Exhortar a los cristianos, ciudadanos de la ciudad temporal y de la ciudad eterna, a cumplir con fidelidad sus deberes temporales, guiados siempre por el espíritu evangélico.

Hermanos, que bella descripción ha hecho de cada uno de nosotros el Concilio: ciudadanos de la ciudad temporal [...]. Pero al mismo tiempo, ciudadanos de la ciudad eterna, desterrados pero, al mismo tiempo, caminando hacia la patria. Se equivocan, dice el Concilio -fíjense bien aquellos que dicen que la Iglesia se meta a la sacristía y no se meta a proclamar los deberes de justicia y a reclamar los derechos humanos de la Humanidad-, se equivocan los cristianos que pretextando que no tenemos aquí ciudad permanente, pues buscamos la futura, consideran que pueden descuidar las tareas temporales sin darse cuenta que la propia fe es un motivo que les obliga al más perfecto cumplimiento de esas tareas, según la vocación personal de cada uno. Aquéllos que dicen: El obispo sólo está predicando política, porque está hablando de derechos humanos, porque está denunciando injusticias, porque está señalándole a los hombres sus deberes políticos, sus derechos de asociación, hermanos, solamente estoy diciendo que, como ciudadanos del cielo, tenemos una conciencia de la cual tenemos que dar cuenta a Dios. Y que haríamos muy mal -entonces sí viviríamos lo que el comunismo dice: la religión, opio del pueblo- cuando quisiéramos decir que, por estar esperando la ciudad futura, vivimos de cualquier manera la ciudad presente [...].

El Concilio dice esta frase -que yo les suplico grabársela profundamente en su corazón-: "El cristiano que falta a sus obligaciones temporales, falta a sus deberes con el prójimo; falta, sobre todo, a

Discurso en la recepción del doctorado honoris causa en Letras por la Universidad de Georgetown el 14 de febrero de 1978 (IV, 15). 
sus obligaciones con Dios y pone en peligro su salvación" [GS 43a]. Lástima que nuestra religión ha traicionado, a veces, el Evangelio. Y por contentar a los grandes señores y a las grandes señoras, les ha dicho que bastaban esos actos de culto y los ha expuesto a perderse para siempre. Estamos volviendo a una religión del auténtico Evangelio $[\ldots]^{48}$.

Para Monseñor, "la comunidad política y la Iglesia son independientes y autónomas, cada una en su propio terreno". Si bien llamadas al diálogo y a la colaboración al servicio del bien común, "la Iglesia siempre será una comunidad distinta porque sus metas están mucho más allá del bien común de la tierra" ${ }^{49}$. Sin embargo, Mons. Romero entendía que la Iglesia, cuya misión no es política, tiene el deber de "meterse en política" cuando así lo exigen "los derechos fundamentales de la persona o la salvación de las almas" (GS 76e). Él se refería a este aspecto de la misión pastoral de la Iglesia, evocando el tema de su discurso en la Universidad de Lovaina (2 de febrero de 1980):

Hay que reflejar siempre el Reino de Dios y su justicia para que los hombres que trabajan en los proyectos de la tierra tengan presente esta iluminación y, a la luz de esta fe, traten de construir también la sociedad de la tierra. Esta es la gran misión de los cristianos en el mundo. Y cuando, en Bélgica, yo decía "la dimensión política de la fe", me refería a esto. Una fe para que sea auténtica tiene que estar metida en las realidades del mundo, pero conservada siempre en Jesucristo" ${ }^{50}$.

\subsection{La resurrección de los muertos y la vida eterna}

"Los que tienen fe y esperanza cristiana saben que detrás de este Calvario de El Salvador está nuestra Pascua, nuestra resurrección y esa es la esperanza del pueblo cristiano" 51 . Usando intencionadamente el doble sentido de la expresión "Calvario de El Salvador", manifestaba su profunda fe Mons. Romero, la víspera de su propio martirio. Fiel al Credo de la Iglesia, en su predicación Mons. Romero proclama la esperanza en la resurrección de los muertos y en la vida eterna, a partir de la fe en la victoria de Cristo resucitado sobre el pecado y la muerte:

\footnotetext{
48 Homilía del 12 de noviembre de 1978 (V, 299-300).

49 Homilia del 28 de octubre de 1979 (VII, 384).

50 Homilía del 10 de febrero de 1980 (VIII, 213).

51 Homilía del 23 de marzo de 1980 (VIII, 360).
} 
Crean en la Resurrección, no duden de que Cristo ha resucitado y que ha salvado, desde su cruz y de su gloria, el pecado de los hombres y la muerte de los hombres. Todos moriremos pero, el que cree en Cristo, no morirá para siempre y allá en el cielo cantaremos la victoria de la inmortalidad ante la cual son pequeñas escaramuzas todas las luchas de las liberaciones de la tierra $[\ldots]^{52}$.

Desarrollando el tema: "la Iglesia, una comunidad en espera activa del Reino de Cristo", Monseñor repasaba las grandes cuestiones de la escatología final (resurrección de los muertos, juicio, vida y muerte eterna) con estas palabras:

[...] para participar en esta fase escatológica, última, definitiva del Reino de Dios, la vida eterna, que ya se inicia en esta tierra, Dios necesita transformar al hombre. Por eso, han de resucitar los muertos. Los que hicieron el bien resucitarán para la vida eterna y los que hicieron el mal resucitarán también para la ignominia y castigo [...] [a los condenados] los transformará de una vida mortal que se acaba con la muerte, en una vida eterna, pero para sufrir eternamente; les dará una inmortalidad de dolor, la segunda muerte que llama la Biblia, estar muriendo sin poder morir. Cosa tremenda de veras, el día del Señor.

No es fantasía, queridos hermanos, esto es lo que le da a nuestra religión su carácter escatológico. Por eso, hemos de vivir pendientes de ese desenlace final $[\ldots]^{53}$.

Inspirado en la escatología neotestamentaria y empleando el lenguaje tradicional propio de los novísimos -aunque resultan verdaderamente plausibles las expresiones "inmortalidad del dolor", "estar muriendo sin poder morir", para referirse a la muerte eterna, evitando la palabra "infierno"-, no obstante, el texto no se separa de la perspectiva del presente, a la que alude por medio de la indicación de que lo eterno "ya se inicia en esta tierra". De acuerdo con la doctrina del Vaticano II, es una preocupación constante de Mons. Romero salvaguardar siempre el sentido de la tensión escatológica frente a las tentaciones tanto escatologistas, como terrestristas ${ }^{54}$. Ese es, según él, el sentido de la esperanza cristiana:

\footnotetext{
Homilia del 17 de febrero de 1980 (VIII, 237).

Homilía del 19 de noviembre de 1978 (V, 310-311).

54 Cf. Homilía del 11 de noviembre de 1979 (VII, 429-430); Homilía del 24 de septiembre de $1978(\mathrm{~V}, 208)$.
} 
Todos tenemos que hacer un esfuerzo por mejorar en esta tierra nuestras situaciones políticas, sociales, económicas, pero siempre con la perspectiva puesta en la eternidad. La esperanza anima para reflejar en la tierra la belleza, la justicia, el amor de aquel Reino. Reflejos, nada más, porque lo verdadero y lo definitivo, solamente se lo reserva la esperanza, y la esperanza es la que anima estos trabajos [...] ¡la esperanza cristiana!

Sin esperanza de Dios son muy mutiladas las liberaciones de la tierra. Sin esperanza de la eternidad las liberaciones solamente se convierten en cambios de dueños de la situación [...]. La meta está más allá de la historia, porque pasando por todas estas liberaciones de la tierra, el hombre no se contentará con ser feliz en la tierra, sino que aspira a una libertad definitiva, a una vida que no muere, a una dignidad que no puede haber otra igual de ser un hijo de Dios. ¿Pues, quién nos lleva hasta esas raíces y quién nos eleva hasta esas alturas? Solamente Cristo. Sin Cristo no hay verdadera liberación ${ }^{55}$.

Como una premonición en la que sería su última misa de fin de año, Mons. Romero se preguntaba en la homilía por lo que traería el año nuevo (!) e, invocando las bendiciones divinas, ofrecía a sus hermanos, congregados en la Nochevieja, una bellísima reflexión -muy marianasobre la eternidad:

¿Qué nos espera el 1980? ¿Será el año de la guerra civil? ¿Será el año de la destrucción total? [...]. Que el Señor tenga ante este porvenir incierto, misericordia de nosotros [...]. Yo les invito, hermanos, en este fin de año, aun ante las perspectivas de dolor, de sufrimiento y de incertidumbres que el tiempo de los hombres nos da, levantarnos a la eternidad de Dios y ver venir de allá su bendición, su Hijo, su perdón, su adopción divina que nos hace sus hijos, sus herederos del cielo, el ofrecimiento de su vida eterna, el destino eterno para el cual estamos llamados. [...]

Allá en el cielo no existe el continuo tránsito del tiempo. El tiempo es una imperfección, el tiempo es lo transitorio, la eternidad es el eterno presente y María vive esa eterna juventud, esa eterna belleza que no se marchita, esa vida que no muere nunca, vida eterna [...] a pesar de que el tiempo pasa, los hombres ya son eternos. Ya son eternos, porque reciben por la fe, por el amor, por la Iglesia, por su oración, por su confianza en Dios, la eternidad que Dios ha traído al tiempo...

55 Homilia del 18 de noviembre de 1979 (VII, 450-451). 
El cristiano ve pasar los años no con nostalgia y sentimentalismo, sino que lo mira con la alegría de quien va caminando hacia el encuentro de la verdadera vida, de la eternidad que no pasa. Así sea ${ }^{56}$.

Para Monseñor Romero la "eternidad" -o su equivalente espacial el "cielo"- no es una sucesión infinita del tiempo, sino un permanente ahora "que no pasa". Este texto representa una magistral traducción en contexto de las palabras iniciales de la Constitución pastoral. En medio de "las tristezas y angustias" del tiempo presente, se abre paso la esperanza gozosa de la vida eterna para aquellos que "ya son eternos" en el tiempo y, sin nostalgias, caminan alegres hacia la Patria celeste (cf. GS 1).

\section{TierRa nUEVA Y CIELO NUEVO (GS 39)}

\section{1. "La aurora del siglo nuevo"}

El Concilio Vaticano II aborda por primera vez en la historia del magisterio de la Iglesia la temática de la "nueva creación". Es en el número final del cap. III de la primera parte, sobre "la actividad humana en el mundo" (GS 39), donde se concentra toda la problemática de la "Nueva tierra" 57 .

GS subraya con insistencia que la esperanza escatológica en una renovación cósmica no solo no ahorra evasivamente la tarea de transformar el mundo, sino que la motiva e impone como una obligación ineludible (cf. GS 21c; 34c; 43a; 57a). Esta idea está ya sugerida en LG 35a y responde implícitamente a la objeción marxista que considera la religión intrínsecamente alienante porque disuade de la liberación socioeconómica (cf. GS 20b). En este contexto, GS 39 trata de establecer una síntesis entre las dimensiones histórica y escatológica de la salvación ${ }^{58}$. Afir-

56 Homilía del 31 de diciembre de 1979 (VIII, 107-109).

57 La expresión fue conservada, a pesar de las objeciones planteadas durante el debate conciliar, porque a juicio de la Comisión redactora, además de reproducir fielmente la terminología bíblica (cf. Is 65,17 ; 2Pe 3,13; Ap 21,1-2), resultaba adecuada para indicar a un tiempo tanto la discontinuidad (GS 39a), como la continuidad (GS 39b) entre la historia y su consumación (cf. Acta Synodalia IV, VII, 438-441).

58 La novedad y complejidad de esta temática se advierte todavía en la labor de artesanía con que, en la redacción final de GS 39 se entrecruzan, integrándose y corrigiéndose mutuamente, sus afirmaciones. Cf. R. SALA, La salvación bumana a la luz del misterio trinitario en la Gaudium et Spes, Ex. Diss. PUG (Valladolid 1999) 124-133. 
ma que la tierra y la humanidad tendrán un cumplimiento definitivo en el que toda la creación será transformada.

Minutos antes de su asesinato, en su última homilía durante el funeral por Sara de Pinto, después de citar íntegramente el texto, el beato Monseñor comentaba GS 39. Sus palabras resuenan como un verdadero testamento espiritual:

Esta es la esperanza que nos alienta a los cristianos. Sabemos que todo esfuerzo por mejorar una sociedad, sobre todo cuando está tan metida esa injusticia y el pecado, es un esfuerzo que Dios bendice, que Dios quiere, que Dios nos exige [...] porque tenemos la seguridad que todo esto que plantamos en la tierra, si lo alimentamos en una esperanza cristiana, nunca fracasaremos, lo encontraremos purificado en el Reino, donde, precisamente, el mérito está en lo que hayamos trabajado en esta tierra [...].

Yo les suplico a todos, queridos hermanos, que miremos estas cosas desde el momento histórico, con esta esperanza, con este espíritu de entrega, de sacrificio, y hagamos lo que podamos [...] vale la pena trabajar porque todos esos anhelos de justicia, de paz y de bien que tenemos ya en esta tierra [...] no se quedan aquí, sino que purificados por el espíritu $[s i c]$ de Dios, se nos recogen y se nos dan en recompensa ${ }^{59}$.

GS 39 consta de tres párrafos. A partir del reconocimiento de las limitaciones del conocimiento humano sobre la materia que se va a exponer, el primero (GS 39a) propone la realidad de la nueva creación y la discontinuidad entre este mundo y el futuro, con un lenguaje casi exclusivamente bíblico. La Constitución pastoral se adentra con cautela en el terreno escatológico. Por eso, no especula sobre lo que se desconoce. Sería una ingenuidad porque humanamente es imposible imaginarse la historia en su situación definitiva y permanente "como si supiésemos lo que va a ser el cielo" ${ }^{\prime 0}$. Sin embargo, GS 39a apunta dos datos incontrovertibles: que el destino último de la historia no implicará la destrucción del universo creado, sino su transformación, y que tanto el amor como su obra permanecerán para siempre (cf. 1 Cor 13, 8; 3, 14).

59 Homilía del 24 de marzo de 1980 (VIII, 386-387).

60 G. Thils, "La actividad humana en el universo (primera parte cap. III)" en Y. Congar- M. Peuchmaurd, ed., Vaticano II. La Iglesia en el mundo de hoy. Constitución pastoral "Gaudium et Spes", vol. II (Cristiandad, Madrid 1970) 370. 
El párrafo segundo (GS 39b) pone de relieve la tensión escatológica del reino de Dios: el mundo futuro -el "siglo nuevo"- no se puede identificar con el progreso terreno, pero tampoco se puede desvincular de los esfuerzos humanos por reflejar su imagen en "esta tierra". Es decir, la "nueva tierra", siendo obra absolutamente gratuita de Dios, no sustituye la creación por "otro" mundo. La nueva creación no surgirá de la nada, sino que será, más bien, recreación de la primera. Como ya se ha indicado anteriormente, Mons. Romero recordaba esta enseñanza conciliar utilizando la imagen de la aurora que anuncia el nuevo día:

A esto estamos llamados, cristianos, a reflejar ya en la peregrinación de la tierra, a través de nuestro sentir y de nuestro vivir escatológico, reflejar -miren qué bonito-, reflejar como la aurora, que no es todavía el sol, pero ya refleja al sol que viene. La vida cristiana debía ser como aurora del siglo nuevo. La vida cristiana, llena de esperanza, llena de fe, llena de santidad, debía de reflejar a los hombres de la historia que no todo se termina en esta tierra, que hay un Reino de Dios hacia el cual caminamos y seremos felices, donde habrá justicia y amor consumados, sin peligros de profanación, pero mientras tanto, no somos más que un vislumbre, una aurora, un anuncio.

El cristiano que no anuncia este sol que viene, no es auténtico cristiano. El cristiano que ofrece una redención, una liberación política, económica (solamente de la tierra) y se olvida de anunciar estos grandes valores de la eternidad, no está dando a los hombres la verdadera liberación ${ }^{61}$.

Según el texto conciliar, aunque hay que distinguir "cuidadosamente" - una redacción anterior de la Constitución pastoral, que fue corregida, decía "totalmente" - el progreso temporal del crecimiento del Reino, "cuanto puede contribuir a mejorar la sociedad humana, interesa en gran medida al reino de Dios" (GS 39b). Recordando a los fieles esta "frase famosa del Concilio Vaticano II", Mons. Romero afirmaba con firmeza que "se opone al proyecto del Reino de Dios, el que unos pocos lo tengan todo y una mayoría no tengan nada" ${ }^{2}$. Y en otra ocasión, con mayor contundencia, si cabe, comentaba ese mismo pasaje de GS a propósito de la idea de "progreso":

${ }_{61}$ Homilia del 19 de noviembre de 1978 (V, 313-314).

62 Homilía del 10 de febrero de 1980 (VIII, 211). 
Los cristianos no somos retrógrados [...] sabemos que los países tienen que progresar. Pero... es necesario que ese progreso se base sobre cimientos de justicia, porque sino la seguridad nacional solamente será seguridad para aquellos que [se] enriquecen y el progreso beneficiará siempre a una minoría. El progreso tiene que beneficiar a todos y para eso se necesita [...] que las leyes, el poder moral del estado no solo reprima [...] y confunda con terrorismo también los esfuerzos justos de los campesinos y de los necesitados. También hay que reprimir, y con fuerza, esas fuerzas reaccionarias que no admiten los cambios sociales, las transformaciones de nuestra sociedad ${ }^{63}$.

\subsection{La transfiguración de la creación}

El párrafo final del cap. III de la Constitución pastoral (GS 39c) comienza enumerando los valores de la dignidad humana, la comunión fraterna y la libertad como bienes representativos de "todos los frutos excelentes de la naturaleza y de nuestro esfuerzo". Se trata de los bienes relacionados con la actividad humana en tanto que transforman al hombre mismo. Coinciden básicamente con los apuntados precedentemente en GS 35a. Seguidamente el texto señala que, mediante el esfuerzo humano individual y colectivo, esos valores humanos deben extenderse universalmente. Tienen como agente difusor en la historia al Espíritu Santo que los orienta hacia su consumación. En consecuencia -prosigue el texto-, "después de haberlos propagado por la tierra en el Espíritu del Señor y de acuerdo con su mandato, volveremos a encontrarlos, limpios de toda mancha, iluminados y transfigurados”. El segundo domingo de Cuaresma de 1980, predicando sobre el episodio evangélico de la transfiguración, Mons. Romero se refería expresamente a esta enseñanza de GS:

Nadie trabaja la tierra y la liberación política de los pueblos con tanto entusiasmo como aquél que espera que las luchas liberadoras de la historia se incorporarán en la gran liberación de Cristo. Cuando sabe que todo lo que reguemos en el mundo -como dice el Concilio- en justicia, en paz, en palabras de amor, en llamamiento a la cordura, todo esto lo encontraremos transfigurado en la belleza de nuestra recompensa eterna ${ }^{64}$.

63 Homilia del 19 de noviembre de 1978 (V, 314).

64 Homilía del 2 de marzo de 1980 (VIII, 291). 
GS expresa la conciencia de que, en el futuro escatológico, el mundo que el mismo ser humano ha creado, "continuando la creación" (cf. GS $34 \mathrm{~b} ; 57 \mathrm{~b})$ y que forma parte de su propia realidad -su "circunstancia", en expresión orteguiana-, no está destinado a desaparecer, sino que participará de su mismo fin último, renovado y purificado. El mundo nuevo será obra y don de Dios pero, al mismo tiempo, será también la consumación de nuestro propio mundo en su amor. No quedará solamente la caridad, sino más precisamente un mundo de caridad, este mundo transfigurado por el amor. Porque "el amor es lo único que puede transformar el mundo", decía Monseñor, "tanto es así, hermanos, que nuestra ocupación en la eternidad será ésa: amar, glorificar, ser felices con Dios, nuestro Señor" ${ }^{\prime \prime}$.

La frase final de GS 39c, "El Reino está ya misteriosamente presente en nuestra tierra; cuando venga el Señor se consumará su perfección", basada en el mensaje central del NT, ofrece la conclusión de todo el cap. III y la síntesis de la escatología de la Constitución pastoral. Frente a visiones reductivas - de signo encarnacionista o escatologista- la escatología realizada y la escatología consecuente se complementan porque son aspectos del mismo misterio. El "Reino" expresa una realidad actual, dinámica y operante en el mundo, no sólo en la Iglesia (cf. LG 5b; GS $22 \mathrm{e}{ }^{66}$. Es una realidad ya presente, pero todavía no definitiva. Solamente con la venida del Señor al fin de los tiempos se implantará como destino último de la historia. La tensión escatológica no se resolverá hasta entonces cuando este mundo será transfigurado en el Reino de Dios y, mundo y Reino, serán una sola cosa (cf. GS 40c; 45b). Por eso, animando a todos a esperar activamente el Reino de Cristo, "para que no nos cansemos nunca de hacer el bien” en este mundo, exclamaba Monseñor, de nuevo en referencia al final de GS 39:

¡Qué bella esperanza! De modo que lo que ahora trabajemos, aun cuando ahora nuestra predicación contracorriente parece como arar en el mar, sabemos que lo vamos a encontrar produciendo muchos

65 Homilía del 10 de julio de 1977 (I-II, 126-127).

66 "La Iglesia no es todo el Reino de Dios... no está más que como un pueblo congregado por Dios en torno de esa jerarquía, pero al servicio del Reino de Dios y del mundo entero, y que por tanto todo su esfuerzo como Iglesia jerárquica no puede concentrarse en una autocontemplación. La Iglesia no es un fin en sí y mucho menos la jerárquica no es un fin en sí. La jerarquía para la Iglesia y la Iglesia para el mundo" (Homilía del 22 de octubre de 1978, V, 257). 
frutos de conversión, de santidad y, sobre todo, espero de veras con la alegría de un cristiano, que todos ustedes se contagien y se solidaricen con esta doctrina de la Iglesia que no es mía, sino de la Iglesia actual. Sigan trabajando por la verdadera dignidad humana, sigan siendo valientes en predicar la doctrina de Cristo, no tengan miedo a las denuncias del pecado en el mundo, encarnen la religión en las realidades de nuestra historia; porque después de haberlo encarnado y trabajado en nuestro mundo, está la promesa de Cristo. Lo encontraremos ${ }^{67}$.

En conclusión, los esfuerzos por mejorar este mundo no se perderán eternamente. No solo quedarán para el mundo futuro nuestras virtudes sobrenaturales, que en el fondo son dones de la gracia divina, sino también el valor propio y objetivo del trabajo humano con el que se contribuye a perfeccionar la creación. Es a lo que se refiere también GS 38 cuando afirma que el servicio terreno a los hombres prepara la "materia" del reino celeste.

\section{Conclusión: DE la PAlabra Al testimonio}

Dice GS 38a que Cristo, "sufriendo la muerte por todos nosotros pecadores, nos enseña con su ejemplo a llevar la cruz que la carne y el mundo echan sobre los hombros de los que buscan la paz y la justicia”. Quien, siguiendo a Jesús, se compromete en favor de la paz y la justicia, experimenta inevitablemente la cruz: tiene que soportar oposición y puede encontrar hasta la muerte. Pero -continúa aquel pasaje de la Constitución pastoral-, como la derrota de la cruz es el preludio de la Resurrección, el poder del Espíritu del Resucitado no solo suscita "el anhelo del siglo futuro", sino que sostiene el trabajo de los que ya preparan aquí la nueva humanidad.

En la eucaristía, el pan y el vino, fruto del trabajo humano sobre la creación, son a su vez transformados en el cuerpo y la sangre de Cristo, el hombre nuevo, mediante una comida que anticipa el banquete escatológico (cf. GS 38b). Con la esperanza de la definitiva liberación escatológica, en el misterio eucarístico Cristo dona ya a la creación una prenda anticipadora de su futura transfiguración.

67 Homilia del 19 de noviembre de 1978 (V, 315). 
"Que este cuerpo inmolado y esta sangre sacrificada por los hombres nos alimente también para dar nuestro cuerpo y nuestra sangre al sufrimiento y al dolor, como Cristo, no para sí, sino para dar conceptos de justicia y de paz a nuestro pueblo" ${ }^{68}$. Fueron las proféticas últimas palabras de Monseñor, como anticipando su inminente oblación. "Numerosos mártires dieron y dan preclaro testimonio de esta fe, la cual debe manifestar su fecundidad imbuyendo toda la vida, incluso la profana, de los creyentes, e impulsándolos a la justicia y al amor, sobre todo respecto del necesitado" (GS 21e). Hablando de los mártires salvadoreños como una "nube de testigos" (LG 50b; cf. Hb 12,1), decía Mons. Romero: "no pensemos, hermanos, que nuestros muertos se han apartado de nosotros; su cielo, su recompensa eterna, los perfecciona en el amor, siguen amando las mismas cosas por las cuales murieron..." ${ }^{69}$. Por eso, la beatificación del Arzobispo mártir representa una valiosa semilla de esperanza para la Iglesia y el sufrido pueblo salvadoreño.

El hombre actual reconoce antes a los testigos que a los maestros; y si escucha a los maestros es porque son también testigos (cf. EN 41). El beato Monseñor fue maestro y testigo, profeta y mártir. Con el testimonio supremo de su martirio autentificó su propio magisterio escatológico. Por eso, sus enseñanzas siguen impactando y suscitando esperanza. Así lo reconocía Henry Nouwen (1932-1996) cuando terminaba el prólogo de una antología de las homilías de Monseñor con el deseo de "que las palabras de Oscar Romero toquen el corazón de quienes las lean y engendren en ellos también aquello nuevo que el mundo espera"70.

\footnotetext{
68 Homilía del 24 de marzo de 1980 (VIII, 587).

69 Homilía del 2 de marzo de 1980 (VIII, 292).

70 Cf. O. Romero, La violencia del amor [edición digital, UCA, San Salvador 2007] xii.
} 
